\title{
Development and Standardization of Polyherbal Formulation for Management of Tuberculosis
}

\author{
M. H. SADHWANI AND VAISHALI SHAH ${ }^{1 *}$ \\ APMC College of Pharmaceutical Education and Research, Motipura, Himatnagar, Sabarkantha, Gujarat 383001, ${ }^{1}$ VIVA \\ institute of Pharmacy, Shirgaon, Virar (East), Vasai, Thane, Maharashtra 401303, India
}

Sadhwani et al.: Development and Standardization of Polyherbal Formulation for Tuberculosis

\begin{abstract}
Tuberculosis is the second most common cause of death from infectious disease. Current antituberculosis treatments consist of long course of combination of antibiotics and toxic side effects and lead to poor patient compliance. So, the present research work has been undertaken for the development and standardization of polyherbal formulation for tuberculosis. In the present study polyherbal formulation was developed using powder of plants of Ocimum sanctum Linn, Tinospora cordifolia (Willd.) Miers, Alstonia scholaris (L.) R.Br and Trikatu churna. The phytochemical screening was performed for presence of various phytoconstituents. Thin Layer Chromatography densitometric methods were developed using High-Performance Thin-Layer Chromatography for the quantifications of gallic acid and piperine in formulation and found to be $0.049 \%$ and $0.051 \%$ respectively in formulation. In vitro antituberculosis activity was performed using Lowenstein Jensen Medium and percentage inhibition at $50 \mu \mathrm{g} / \mathrm{ml}, 500 \mu \mathrm{g} / \mathrm{ml}$ and $1000 \mu \mathrm{g} / \mathrm{ml}$ was found to be $11.71 \%$, 74.15\% and $94.11 \%$ respectively. Results showed dose dependant in vitro antituberculosis activity. These activities may be due to the presence of various phytoconstituents like flavonoids, tannins and phenoilc in formulations. Above results also support the rational use of above plants as antituberculosis.
\end{abstract}

Key words: Antituberculosis, Tinospora cordifolia, Alstonia scholaris, Ocimum sanctum, Trikatu churna

Tuberculosis is an infectious disease caused by various strains of mycobacteria, usually Mycobacterium tuberculosi ${ }^{[1]}$. Approximately 8-10 million people are infected with this pathogen every year ${ }^{[2]}$. The most common antibiotics used in the treatment of tuberculosis are isoniazid, rifampicin and streptomycin. Current antituberculosis treatments process a long course of a combination of antibiotics and toxic side effects and lead to poor patient compliance. There is now a need to discover and develop new safe and herbal antituberculosis drugs.

The medicinal property of plant offers a new source of potent anti-microbial agent in the form of secondary metabolite. This include the different classes of compound, such as saponins, steroids peptides, alkaloids, coumarins and flavones, alcohols obtained from plants. Anti-tuberculosis activity has been reported in number of higher plants ${ }^{[3]}$. So, the present research work has been undertaken for the development and standardization of polyherbal formulation for tuberculosis. The formulation consists of Alstonia scholaris, Ocimum sanctum, Tinospora cordifolia and Trikatu churna.

*Address for correspondence

E-mail: vnshah02@gmail.com

September-October 2021
Alstonia scholaris is used to treat many diseases such as malaria, chronic diarrhoea, fever, asthma, etc., also its anti-mycobacterial activity of the bark of Alstonia scholaris has been reported ${ }^{[4,5]}$. Ocimum sanctum is used for cough and asthma, so it may cure some symptoms of tuberculosis and the plant extract of Ocimum sanctum shows in vitro anti tubercular activity ${ }^{[6,7]}$. Tinospora cordifolia is an immunomodulatory drug ${ }^{[8,9]}$. Trikatu churna contains piperene as an important phytoconstituents and anti-mycobacterial activity of piperene has also been reported ${ }^{[10,11]}$. All these drugs are used in tuberculosis individually, so in this research study the polyherbal formulation was prepared for management of tuberculosis. Estimation of gallic acid and piperine was done by High-Performance Thin-Layer Chromatography (HPTLC) method in This is an open access article distributed under the terms of the Creative
Commons Attribution-NonCommercial-ShareAlike 3.0 License, which
allows others to remix, tweak, and build upon the work non-commercially,
as long as the author is credited and the new creations are licensed under
the identical terms

Accepted 19 October 2021

Revised 13 July 2021

Received 03 April 2020

Indian J Pharm Sci 2021;83(5):1051-1056 
formulation. Formulation was evaluated for its antitubercular activity using in vitro anti-microbial assay using H37Rv strain.

\section{MATERIALS AND METHODS}

\section{Materials:}

All the chemicals and solvent used in the experiments were of analytical grade. Gallic acid and piperine was collected form Natural Remedies Pvt Ltd. (Bangalore, India).

\section{Collection and authentication of plant materials:}

Alstonia scholaris (Bk), Ocimum sanctum (L), Tinospora cordifolia (St) and Zingiber officinale (rh) were collected from Himatnagar, Sabarkantha district of Gujarat, India. The fruit of Piper nigrum and Piper longum were procured from market. Their identities were confirmed at the Department of Botany by Dr M.M. Prajapati, Himatnagar, Gujarat, India.

\section{Development of formulation:}

The drugs of plant origin were dried and made into fine powders, separately. Trikatu churna was prepared by mixing fine powders of Piper nigrum, Piper longum and Zingiber officinale in equal proportions. The fine powder of remaining drugs and Trikatu churna were taken in equal proportion and polyherbal formulation is prepared (Table 1).

\section{Standardization of the developed formulation:}

Physicochemical \& phytochemical screening of formulation: Physicochemical parameters of formulation was done as per the who guideline includes alcohol and water soluble extractive value and ash value $^{[12,13]}$. Preliminary Phytochemical screening of formulation was done for the presence of different phytoconstituents by chemical test ${ }^{[14]} \&$ Thin Layer Chromatography (TLC) ${ }^{[15]}$.

Quantification of polyphenol and total flavonoids: Stock solution of polyherbal formulation $1 \mathrm{mg} /$ ml was prepared in methanol and used for the estimation of polyphenol and flavonoids.

Polyphenol content: Total phenol content in plant extract is generally determined according to folin ciocalteu method ${ }^{[16]}$. This colorimetric method is based on the reduction of a phosphotungstate phosphomolybdate complex by phenolic to blue colour product in alkaline condition. Each of $100 \mu \mathrm{l}$ of sample
TABLE 1: COMPOSITION OF FORMULATION

\begin{tabular}{lccc}
\hline S. No & Ingredients & Part of plant & Quantity \\
\hline 1 & Alstonia scolaris & Bark & 1 part \\
2 & Ocimum sanctum & Leaves & 1 part \\
3 & Tinispora cordifolia & Stem & 1 part \\
& $\begin{array}{c}\text { Trikatu churna } \\
\text { (Zingiber officinale (rh), } \\
4\end{array}$ & Piper longum \& Piper \\
nigrum (fruit)) & - & 1 part \\
& & & \\
\hline
\end{tabular}

was taken in $25 \mathrm{ml}$ volumetric flask, to which $10 \mathrm{ml}$ of water and $1.5 \mathrm{ml}$ of folin ciocalteau reagent were added. The mixture was then kept for $5 \mathrm{~min}$. And $4 \mathrm{ml}$ of $20 \% \mathrm{w} / \mathrm{v}$ sodium carbonate solution was added. The volume was made up to $25 \mathrm{ml}$ with double distilled water. The mixture was kept for 30 min until blue colour developed. The samples were then observed at $765 \mathrm{~nm}$ in Ultraviolet (UV)-visible spectrometer Shimadzu, UV-1601, Japan. The percentage total phenolic content was calculated from calibration curve of gallic acid plotted under similar procedure.

Total flavonoids: Aluminium chloride $\left(\mathrm{AlCl}_{3}\right)$ colorimetric method was used for flavanoid determination $^{[17]}$. The method is based on the quantification of yellow colour produced by interaction of flavanoids with $\mathrm{AlCl}_{3}$ reagent. $1 \mathrm{ml}$ of sample from stock solution was mixed with $3 \mathrm{ml}$ methanol, $0.2 \mathrm{ml}$ of $10 \% \mathrm{AlCl}_{3}, 0.2 \mathrm{ml}$ of $1 \mathrm{M}$ potassium acetate and $5.6 \mathrm{ml}$ distilled water. The solution was maintained at room temperature for $30 \mathrm{~min}$; the absorbance of the reaction mixture was measured at $415 \mathrm{~nm}$ with UV-Visible spectrophotometer. The percentage of total flavanoid was calculated from calibration curve of standard flavanoid (rutin) plotted under similar procedure.

Quantification of gallic acid and piperine in polyherbal formulation by HPTLC:

Spotting device-Linomat V Automatic Sample Spotter, CAMAG (Muttenz, Switzerland); Syringe: $100 \mu 1$ Hamilton (Bonadzu, Switzerland); TLC ChamberGlass with trough chamber $(20 \times 10 \times 4 \mathrm{~cm})$, CAMAG; Densitometer-TLC scanner 3 linked to WinCats Software, CAMAG; HPTLC plates $-10 \times 10 \mathrm{~cm}, 0.2 \mathrm{~mm}$ thickness pre-coated with silica gel 60 F254, Merck; KgaA, Cat. No. 1.05548 (Darmstadt, Germany); Experimental conditions: Temperature $25 \pm 2^{\circ}$, relative humidity $40 \%$

A stock solution of both was prepared by dissolving $10 \mathrm{mg}$ of drug in methanol and making up the volume to $10 \mathrm{ml}$ with methanol to get the final concentration of 
$1 \mathrm{mg} / \mathrm{ml}$. From this stock solution standard solution of $4-15 \mu \mathrm{g} / \mathrm{ml}$ were prepared by transferring aliquots $(0.2-$ $1.5 \mathrm{ml}$ ) of stock solution to $10 \mathrm{ml}$ volumetric flasks and adjusting the volume to $10 \mathrm{ml}$ with methanol.

Sample solutions was prepared by dissolving $100 \mathrm{mg}$ of the extract of formulation in methanol and making up the volume to $10 \mathrm{ml}$ to get the concentration of $10 \mathrm{mg} / \mathrm{ml}$.

Different concentration of the standard solution was applied in triplicate on silica gel 60 F254 plate (E. Merck) (0.2 mm thickness) with the CAMAG Linomat V Automatic sample Spotter. The plate was developed in a solvent system of Toluene:Ethyl acetate:Formic acid:Methanol (3:4:0.8:0.2) at $25 \pm 20^{\circ}$ temperature and $40 \%$ relative humidity and allowed to travel up to a distance of $8 \mathrm{~cm}$. After development the plate was dried in air and scanned densitometrically at $254 \mathrm{~nm}$ for gallic acid \& piperine. The peak areas were recorded. Calibration curve of gallic acid and piperine was prepared by plotting peak areas vs. concentration. The amount of gallic acid and piperine in the sample was calculated using the respective calibration curve.

\section{Validation of analytical methods:}

Validation of the developed HPTLC method was carried out as per the International Conference on Harmonization (ICH) guidelines Q2 (R1) for specificity, sensitivity, accuracy, precision and repeatability ${ }^{[18,19]}$.

\section{In vitro anti-tuberculosis activity:}

In vitro anti-tuberculosis activity was performed by using Lowenstein Jensen method (Proportion method). The water extract of formulation was subjected to screening by Lowenstein Jensen Method using H37Rv strain of Mycobacterium tuberculosis (M. tuberculosis) (Lowenstein Jensen Medium (LJ Medium)). The 10 -fold dilution of standard $1 \mathrm{mg} / \mathrm{ml} \mathrm{M}$. tuberculosis suspension $\mathrm{H} 37 \mathrm{Rv}$ were streaked on $\mathrm{LJ}$ medium for determining Colony Forming Unit (CFU) in the presence and absence of plant extracts.

The formulation extract was incorporated in the medium at concentration of $50 \mu \mathrm{g} / \mathrm{ml}, 500 \mu \mathrm{g} / \mathrm{ml}$ and $1000 \mu \mathrm{g} / \mathrm{ml}$ prior to inspissation. The medium set inoculated with the standard bacterial suspension and incubated at $37^{\circ}$ for $21 \mathrm{~d}$. For comparison, extract free control slants were used. Percentage inhibition was calculated by mean reduction in number of colonies on extract containing as compared to extract free controls $^{[20,21]}$. All above mentioned activity was done as

per the specification for Biosafety level cabinet 2 for infectious organism.

\section{RESULTS AND DISCUSSION}

In present study we have developed polyherbal formulation and it was standardized using simple quantitative techniques.

Physicochemical parameters of polyherbal formulation showed in Table 2. Alcohol soluble extractive $(10.41 \%)$ is more than water soluble extractive (9.7\%). Phytochemical analysis of formulation by chemical test was shown in Table 3 for the presence of various phytoconstituents includes tannin, phenolic, flavonoid \& saponin, Phytochemical screening by TLC was done by solvent system Toluene:Ethyl acetate:Methanol:Formic acid (3:4:0.2:0.8). Results were shown in Table 4 . In the present investigation physicochemical parameters like ash value (Total ash \& acid insoluble ash) and extractive value (water \& alcohol soluble) of formulation was done for the standardization of formulation, chemical test and TLC gives the presence of various phytoconstituents.

Total phenolic and flavonoid content were calculated by using calibration curve data for gallic acid (Table 5) and rutin respectively (Table 6). Oxidative stress plays an important role in the pathogenesis of tuberculosis besides other chronic ailments owing to the reasons: result of tissue inflammation, poor dietary intake, free radicals burst from activated macrophages, poor

TABLE 2: PHYSICAL PARAMETER OF POLYHERBAL FORMULATION

\begin{tabular}{lcc}
\hline S. No. & Physical Parameters & $\% \mathrm{w} / \mathrm{w} \pm$ SD $(\mathrm{n}=3)$ \\
\hline 1 & Total ash & $2.16 \pm 0.28$ \\
2 & Acid insoluble ash & $0.31 \pm 0.02$ \\
3 & Water soluble ash & $0.75 \pm 0.05$ \\
4 & Alcohol soluble extractive & $10.4 \pm 0.28$ \\
5 & Water soluble extractive & $9.7 \pm 0.2$ \\
\hline
\end{tabular}

TABLE 3: QUALITATIVE CHEMICAL INVESTIGATION OF FORMULATION

\begin{tabular}{lccc}
\hline S. No. & Phytochemical Nature & $\begin{array}{c}\text { Methanol } \\
\text { extract }\end{array}$ & $\begin{array}{c}\text { Water } \\
\text { extract }\end{array}$ \\
\hline 1 & Alkaloids & + & + \\
2 & Proteins and amino acids & + & + \\
3 & Carbohydrates & + & + \\
4 & Flavonoids & + & + \\
5 & Tannins (Phenolic & + & + \\
6 & Compounds) & - & - \\
7 & Fixed oils \& Fats & + & + \\
\hline
\end{tabular}


www.ijpsonline.com

TABLE 4: TLC FINGERPRINTING OF METHANOLIC EXTRACT OF FORMULATION

\begin{tabular}{lcc}
\hline Detection & Rf value & Inference \\
\hline UV light at $254 \mathrm{~nm}$ & $0.69,0.71,0.8$ & - \\
UV light at $366 \mathrm{~nm}$ & $0.35,0.41,0.69,0.75,0.8$ & - \\
Ferric chloride & 0.65 & Tannins \\
Dragendorff reagent & $0.14,0.26,0.8$ & Alkaloids \\
Vanillin sulphuric acid & $0.14,0.19,0.71,0.78,0.88$ & Triterpenoids \\
Anisaldehyde sulphuric Acid & $0.14,0.21,0.64,0.67,0.78,0.85,0.90,0.94$ & Bitter principles \\
\hline
\end{tabular}

Note: Solvent system:Toluene:Ethyl acetate:Methanol:Formic acid (3:4:0.2:0.8)

TABLE 5: CALIBRATION CURVE DATA FOR GALLIC ACID (CONCENTRATION vs. ABSORBANCE)

\begin{tabular}{lc}
\hline Conc of gallic acid & Absorbance $\pm S D(n=3)$ \\
\hline 20 & $0.094 \pm 0.001$ \\
40 & $0.2 \pm 0.02$ \\
60 & $0.28 \pm 0.015$ \\
80 & $0.37 \pm 0.02$ \\
100 & $0.49 \pm 0.01$ \\
\hline
\end{tabular}

Note: Correlation coefficient: 0.995; Slope: 0.0048; Intercept: 0.0018

TABLE 6: CALIBRATION CURVE DATA FOR RUTIN (CONCENTRATION vs. ABSORBANCE)

\begin{tabular}{lc}
\hline Conc of Rutin $((\mu \mathrm{g} / \mathrm{ml})$ & Absorbance \pm SD $(\mathrm{n}=3)$ \\
\hline 20 & $0.051 \pm 0.01$ \\
40 & $0.087 \pm 0.01$ \\
60 & $0.145 \pm 0.003$ \\
80 & $0.195 \pm 0.02$ \\
100 & $0.25 \pm 0.01$ \\
\hline
\end{tabular}

Note: Correlation coefficient: 0.9954; Slope: 0.0025; Intercept: 0.0062

immunity etc., ${ }^{[22]}$. Plants containing flavonoids and polyphenolics are known to possess strong antioxidant properties. Hence in the present study polyphenolic and flavonoid content were estimated. Significant amount of polyphenolic $(0.61 \% \mathrm{w} / \mathrm{w})$ and flavonoid compound $(0.53 \% \mathrm{w} / \mathrm{w})$ were present in formulation, which attributes to its rationality of possessing antioxidant activity.

Formulation was standardized by using marker compound. TLC densitometric methods were developed using HPTLC for the quantification of gallic acid \& piperine marker compounds from the formulation. Solvent systems were optimized to achieve best resolution of the marker compounds from other components of the sample extract. Of the various solvent system tried, one containing solvent system-Toluene: Ethyl acetate:Methanol:Formicacid (3:4:0.2:0.8) gave best resolution of gallic acid $\left(\mathrm{R}_{\mathrm{f}}=0.65\right)$ and Piperine $\left(\mathrm{R}_{\mathrm{f}}=0.78\right)$ in the presence of other compounds in the sample extract and enabled the quantification of marker compounds. The identity of the bands in the sample extracts were confirmed by comparing the $\mathrm{Rf}$ and the absorption spectra by overlaying their UV absorption spectra with those of their respective standards. HPTLC chromatogram for gallic acid and piperine was shown in fig. $1 \&$ fig. 2 respectively. Estimation of gallic acid and piperine was shown in Table $7 \&$ Table 8 respectively. Gallic acid and piperine was found to be $0.049 \%$ \& $0.051 \%$ respectively. The method was validated in terms of Linearity, Precision and Limit of detection, Limit of quantification, Accuracy and specificity. Summary of validation parameters were shown in Table 9. Formulation was standardized by using marker compound. TLC densitometric methods were developed using HPTLC for the quantification of gallic acid \& piperine marker compounds from the formulation. The method was found to be suitable for the quantification of these marker compounds in the raw materials and formulation.

The result of the antimycobacterial activity by $\mathrm{LJ}$ medium is presented in Table 10 against H37Rv a standard strain of $M$. tuberculosis. Average growth and percentage inhibition of $M$. tuberculosis H37Rv by LJ proportion method on water extract and extract free control LJ slants, after $21 \mathrm{~d}$ of incubation at $37^{\circ}$ were recorded. Inhibition of $M$. tuberculosis H37Rv was observed for all this concentration. Consistent reduction in CFU against $\mathrm{H} 37 \mathrm{Rv}$ strains were observed for all the concentrations $50 \mu \mathrm{g} / \mathrm{ml}, 500 \mu \mathrm{g} / \mathrm{ml}$, $1000 \mu \mathrm{g} / \mathrm{ml}$. The maximum percentage inhibition was found $94.11 \%$ at $1000 \mu \mathrm{g} / \mathrm{ml}$. Data shown in Table 10 . The formulation showed dose dependent inhibition of growth of M. Tuberculosis. This activity may be due to the presence of tannin and flavonoid compounds, also due to significant amount of bioactive compound gallic acid which is reported for antioxidant activity and piperine which was also reported for anituberculosis activity ${ }^{[23]}$. Above results also support the rational use of above plants in formulation for the management of anti-tuberculosis. 


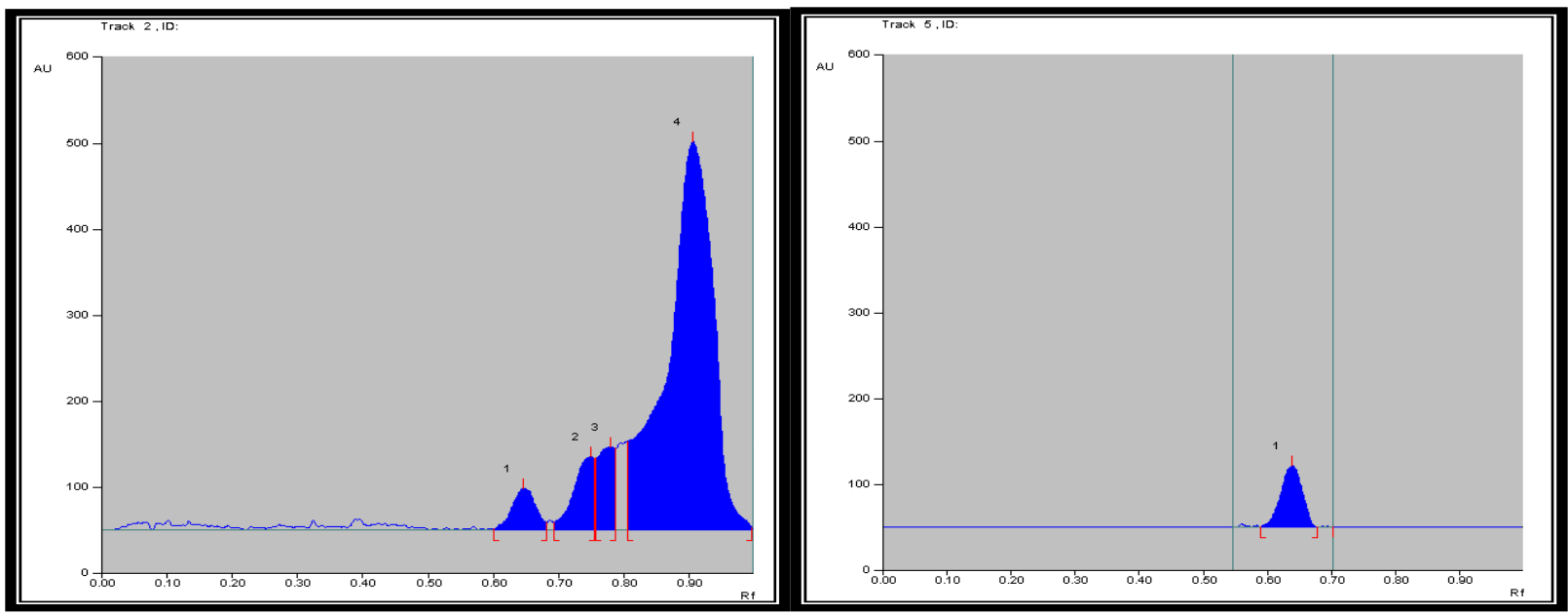

Fig 1: HPTLC Chromatogram of formulation and standard gallic acid $\left(R_{\mathrm{f}}: 0.65\right)$

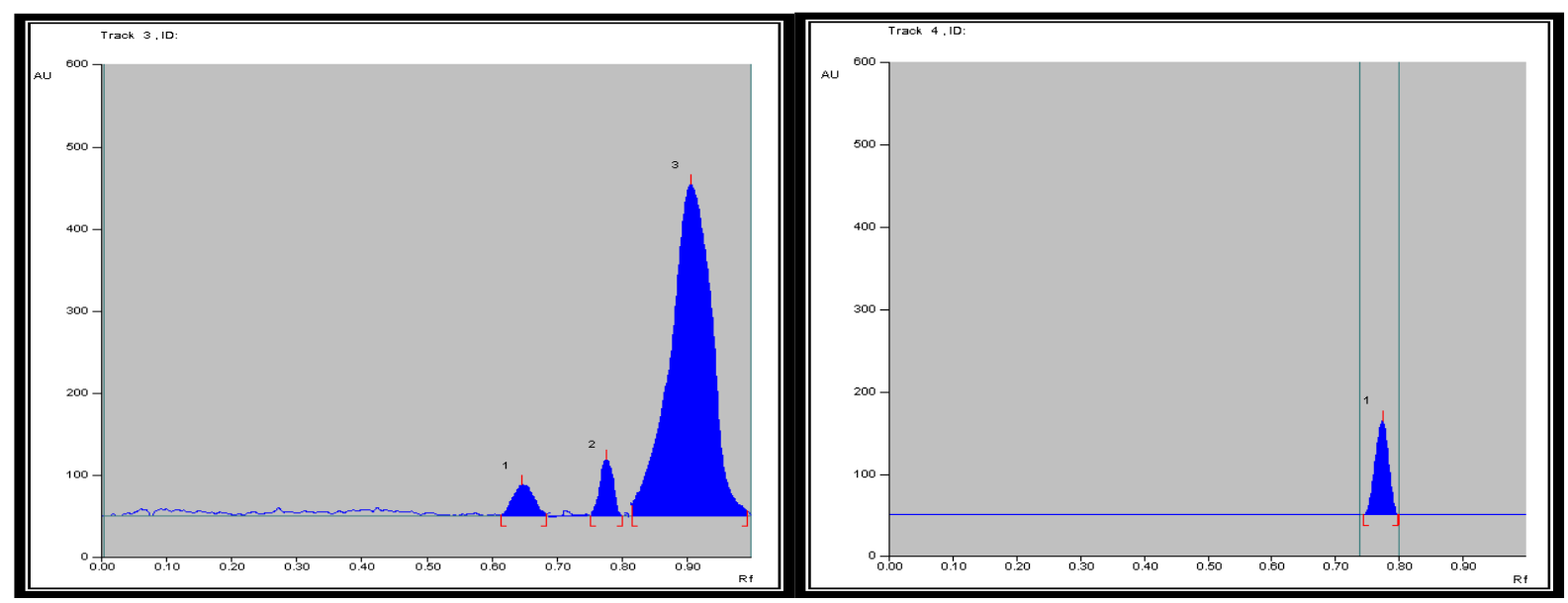

Fig 2: HPTLC Chromatogram of formulation and piperine $\left(R_{\mathrm{f}}: \mathbf{0 . 7 8}\right)$

TABLE 7: CALIBRATION CURVE DATA FOR GALLIC ACID BY HPTLC (CONCENTRATION vS. PEAK AREA)

\begin{tabular}{lcc}
\hline $\begin{array}{l}\text { Concentration of gallic } \\
\text { acid }(\mathrm{ng} / \mathrm{spot})\end{array}$ & $\begin{array}{c}\text { Peak area } \pm \text { SD } \\
(\mathrm{n}=3)\end{array}$ & $\begin{array}{c}\text { Coefficient of } \\
\text { variance }(\% \mathrm{CV})\end{array}$ \\
\hline 400 & $1320.9 \pm 25.89$ & 1.96 \\
600 & $1546.1 \pm 23.54$ & 1.52 \\
800 & $1854.3 \pm 32.8$ & 1.76 \\
1000 & $2049.1 \pm 40.1$ & 1.95 \\
1500 & $2536.9 \pm 31.6$ & 1.24 \\
\hline
\end{tabular}

Note: Correlation coefficient: 0.9916; Slope: 1.109; Intercept: 907.69, Values are expressed as mean $\pm S D(n=3)$

TABLE 8: CALIBRATION CURVE DATA FOR PIPERINE (CONCENTRATION vs. PEAK AREA)

\begin{tabular}{lcc}
\hline $\begin{array}{l}\text { Concentration of gallic } \\
\text { acid (ng/spot) }\end{array}$ & Peak area \pm SD $(n=3)$ & $\%$ CV \\
\hline 400 & $2136.8 \pm 40.3$ & 1.88 \\
600 & $2508.8 \pm 35.2$ & 1.40 \\
800 & $2935.8 \pm 39.45$ & 1.34 \\
1000 & $3256.4 \pm 41.6$ & 1.27 \\
1500 & $4025.2 \pm 39.8$ & 0.98 \\
\hline
\end{tabular}

Note: Correlation coefficient: 0.9949; Slope: 1.7144; Intercept: 1498.2, Values are expressed as mean $\pm S D(n=3)$
TABLE 9: SUMMARY OF VALIDATION PARAMETERS FOR GALLIC ACID AND PIPERINE

\begin{tabular}{lcc}
\hline Parameters & Gallic acid & Piperine \\
\hline Linearity & 0.991 & 0.994 \\
(Correlation-coefficient) & 1.65 & 1.96 \\
Repeatability of measurement & $1.26-1.74$ & $0.76-1.57$ \\
Intra-day precision & $1.16-1.71$ & $0.65-1.51$ \\
Inter-day precision & 33.83 & 53.09 \\
Limit of Detection (ng/spot) & 102.52 & 160.90 \\
Limit of Quantification (ng/spot) & $98.89 \pm 0.747$ & $98.83 \pm 0.7$ \\
Accuracy & $400-1500$ & $400-1500$ \\
Range (ng/spot) & Specific & Specific \\
Specificity & &
\end{tabular}

TABLE 10: RESULTS OF IN VITRO ANTI TUBERCULOSIS ACTIVITY

\begin{tabular}{ccccccc}
\hline \multicolumn{4}{c}{ LJ proportion method } \\
\hline \multicolumn{4}{c}{ CFU on media } & \multicolumn{4}{c}{$\%$ Inhibition } \\
\hline \multirow{2}{*}{ Control } & 50 & 500 & 1000 & 50 & 500 & 1000 \\
& $\mu \mathrm{g} / \mathrm{ml}$ & $\mu \mathrm{g} / \mathrm{ml}$ & $\mu \mathrm{g} / \mathrm{ml}$ & $\mu \mathrm{g} / \mathrm{ml}$ & $\mu \mathrm{g} / \mathrm{ml}$ & $\mu \mathrm{g} / \mathrm{ml}$ \\
51 & 45 & 13 & 3 & 11.71 & 74.15 & 94.11 \\
\hline
\end{tabular}




\section{Acknowledgements:}

Author thanks to Micropharm diagnostic center, Gandhinagar, Gujarat. For theirhelp in antimycobacterial activity.

\section{Conflicts of interest:}

The authors declared no conflicts of interest.

\section{REFERENCES}

1. Kumar V, Abbas AK, Fausto N, Mitchell RN. Robbins Basic Pathology. $8^{\text {th }}$ Edition, Saunders Elsevier, Philadelphia; 2007. p. 516-22.

2. The World health report: Making a difference, World Health Organization; 1999. p. 110.

3. Jimenez-Arellanes A, Meckes M, Ramirez R, Torres J, LunaHerrera J. Activity against multidrug-resistant Mycobacterium tuberculosis in Mexican plants used to treat respiratory diseases. Phytother Res 2003;17(8):903-8.

4. Antony M, James J, Misra CS, Mundur Sagadevan LD, Thaliyil Veettil AK, Thankamani V. Anti-mycobacterial activity of the plant extracts of Alstonia scholaris. Int J Curr Pharm Res 2012;4(1):40-2.

5. Iwo MI, Soemardji AA, Retnoningrum DS, Sukrasno UMU. Immunostimulating effect of pule (Alstonia scholaris L. R.Br., Apocynaceae) bark extracts. Clin Hemorheol Microcirc 2000;23(2-4):177-83.

6. Ubaid RS, Anantrao KM, Jaju JB, Mateenuddin MD. Effect of Ocimum sanctum (OS) leaf extract on hepatotoxicity induced by antitubercular drugs in rats. Indian J Physiol Pharmacol 2003;47(4):465-70.

7. Taghi N, Mohagheghi A, Zahedani S, Naderi M, Moud B. Antituberculosis effect Of Ocimum sanctum extracts in in vitro and macrophage culture. J Med Sci 2006;6(3):348-51.

8. Methew S, kuttan G. Antioxidant activity of Tinospora cordifolia and its usefulness in the amelioration of cyclophosphamide induced toxicity. J Exp Clin Cancer Res 1997;16(4):407-11.

9. Thatte UM, Dahanukar SA. Immunotherapeutic modification of experimental infections by Indian medicinal plants. Phytother Res 1989;3(2):43-9.
10. Swapna DP, Junise V, Shibin P, Senthila S, Rajesh RS. Isolation, identification and antimycobacterial evaluation of piperine from Piper longum. Pharm Lett 2012;4(3):863-8.

11. Reddy BU, Seetharam YN. Antimicrobial and analgesic activities of Trikatu Churna and its ingredients. Pharmacol Online 2009;3:489-95.

12. Quality control methods for medicinal plant materials. 1st ed. WHO Guidelines AITBS Publishers and distributors, Delhi; 2002. p. 40-3.

13. Quality control methods for medicinal plant materials. 1st ed. WHO Guidelines AITBS Publishers and distributors, Delhi; 2002. p. 45-6.

14. Khandelwal KR. Practical Pharmacognosy. 12th ed. Nirali Prakashan, Pune; 2004. p. 149-56.

15. Wagner H, Bladt S. Screening of unknown commercial drugs. Plant drug analysis: a thin layer chromatography atlas 2 nd ed, Thomson press, India, 2002. p. 349-54.

16. Hergerman A, Mueller IH, Makkar HP. Quantification of tannins in tree foilage-a laboratory manual. FAO/536 IAEA Vienna 2000;537:4-7.

17. Chang C, Yang M, Wen H, Chern J. Estimation of total flavanoid content in propels two complementary colorimetric methods. J Food Drug Anal 2002;10:178-82.

18. ICH Harmonized Tripartite Guidelines. Validation of Analytical Procedures: Text and Methodology, Q2 (R1); 2005. p. 1-13.

19. World Health Organization guidelines. Validation of analytical procedures used in examination of pharmaceutical materials, 32nd report; 1992.

20. Gupta R, Thakur B, Singh P, Singh HB, Sharma VD, Katoch $\mathrm{VM}$, et al. Anti-tuberculosis activity of selected medicinal plants against multi-drug resistant Mycobacterium tuberculosis isolates. Indian J Med Res 2010;131(6):809-13.

21. Indian Pharmacopoeia, Government of India, Ministry of Health \& Family Welfare; Ghaziabad, 6th ed. 2010;1:34,35.

22. Jack CI, Jackson MJ, Hind CR. Circulating markers of free radical activity in patients with pulmonary tuberculosis. Tuber Lung Dis 1994;75(2):132-7.

23. Hegeto LA, Caleffi-Ferracioli KR, Nakamura-Vasconcelos $\mathrm{SS}$, de Almeida AL, Baldin VP, Nakamura CV, et al. In vitro combinatory activity of piperine and anti-tuberculosis drugs in Mycobacterium tuberculosis 2018;111:35-40.. 